\title{
Highly efficient three-phase grid-connected parallel inverter system
}

\author{
Evren ISEN $^{1}$, Ahmet Faruk BAKAN ${ }^{2}$
}

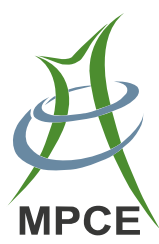

\begin{abstract}
In this paper, a new three-phase grid-connected inverter system is proposed. The proposed system includes two inverters. The main inverter, which operates at a low switching frequency, transfers active power to the grid. The auxiliary inverter processes a very low power to compensate for the grid current ripple. Thus, no active power is processed by the auxiliary inverter. The goal is to produce a grid current with a low total harmonic distortion (THD) and to obtain the highest efficiency from the inverter system. The main inverter is controlled via a space-vector pulse-width modulation owing to its optimum switching pattern, and the auxiliary inverter is controlled via a hysteresis current-control technique owing to the technique's fast dynamic response. The proposed system is analyzed in terms of different DC-link voltage, switching frequency, and filter inductance values. The optimum system parameters are selected that provide a THD value of less than $5 \%$. A prototype inverter system at a $10-\mathrm{kW}$ output power has been implemented. The main inverter operates at a $3-\mathrm{kHz}$ switching frequency, and the auxiliary inverter compensates for the grid-current ripple. In total, a THD of $4.33 \%$
\end{abstract}

CrossCheck date: 27 December 2017

Received: 18 July 2017/Accepted: 27 December 2017/Published online: 5 March 2018

(C) The Author(s) 2018. This article is an open access publication

$\triangle$ Evren ISEN

evren.isen@klu.edu.tr

Ahmet Faruk BAKAN

fbakan@yildiz.edu.tr

1 Department of Electrical and Electronics Engineering, Kirklareli University, Kirklareli, Turkey

2 Department of Electrical Engineering, Yildiz Technical University, Istanbul, Turkey and an efficiency of $97.86 \%$ are obtained using the proposed inverter system prototype.

Keywords Active filter, Inverter efficiency, Ripple cancellation, Three-phase grid-connected inverter

\section{Introduction}

The energy obtained from alternative energy sources is transferred to power grids through inverters. In high-power applications, three-phase inverters are used, and in lowpower applications, single-phase inverters are used [1,2]. Voltage-source inverters are widely used in grid-connected systems owing to their simplicity and reliability. Threephase voltage source inverters can be implemented as three-wire, four-wire, and four-leg systems [3-6].

Grid-connected inverters are expected to have high power quality, high efficiency, and high reliability in renewable energy applications. Therefore, inverter topology and control techniques play important roles in gridconnected systems.

Voltage-source inverters are connected to the grid via filters. Different filters can be selected between inverters and grids, such as L, LC, and LCL filter. The L filter allows the use of a simple current-control strategy in the inverter. There is only one control loop, and grid current is used as a feedback signal. However, the inverter must operate at a relatively high switching frequency, or a high-value $\mathrm{L}$ filter must be used to meet the harmonic standards such as IEEE 929-2000 and IEEE 519. Because a high switching frequency causes high switching losses, L filters are not utilized in high-power renewable applications. To increase the harmonic attenuation of the L filter, an LC filter is used with an isolation transformer, but it is not generally used in 
grid-connected inverters, unlike stand-alone inverters. The lowest total harmonic distortion (THD) value is obtained with LCL filters at the same frequency compared with other filters. However, the LCL filter design is quite complicated owing to resonance and reactive power problems. It is important to determine filter component values in order to prevent resonance and to decrease reactive power generated by capacitors [7-9]. Additional passive damping techniques and complex control algorithms are used to suppress resonance. In the passive damping technique, additional resistance, capacitance, and/or inductance are required $[10,11]$. Current and voltages of the capacitor and inductances are used in the control algorithm. Thus, an additional two or more control loops make the control algorithm more difficult [12].

In medium and large power-inverter applications, neutral point clamped (NPC) inverters are preferred because of their low voltage stress and low switching losses. NPC inverters have three voltage levels, i.e., $-V_{\mathrm{dc}} / 2,0$, and $V_{\mathrm{dc}} /$ 2 , and thus, the voltage drop on switching devices is reduced. Therefore, switching losses decrease. However, the control algorithm becomes more complex and conduction losses increase because of a series connection of two switches on the upper and lower arms in NPC inverters $[13,14]$.

Grid synchronization is important for grid-connected inverters. The synchronization algorithm determines the grid angle that is used for rotating reference-frame $(d q)$ conversion. Reference voltages and currents are produced using the angle to meet the power-quality standards. Different synchronization algorithms are used in the literature. The atan algorithm is a simple method for detecting the grid angle. It is realized in two different frames, $d q$ and $\alpha \beta$. The reference frame components are filtered, and the $\alpha \beta$ components of the grid voltage are used in an atan trigonometric function to calculate the angle. The disadvantages of the method are its poor performance in the case of fluctuating frequency and unbalanced grid voltage [15]. In recent years, the widely used synchronization technique, which has synchronous rotating frame phase-locked loops (SRF-PLLs), has been utilized. It has good performance when the grid voltage is balanced and not polluted by harmonics. Such disturbances affect the SRF-PLL dynamic-response performance [16]. Different filtering techniques are used to enhance the performance of SRFPLL under distorted and unbalanced grid-voltage conditions $[17,18]$.

In this study, a new highly efficient three-phase gridconnected parallel inverter system is proposed. The proposed system is developed for grid-connected systems owing to the importance of efficiency in renewable energy systems. The proposed system includes two inverters. The main inverter operates at low switching frequency and transfers active power to the grid, while the auxiliary inverter compensates for the grid-current ripple. Thus, no active power is processed by the auxiliary inverter, and the current is lower compared with the main inverter. Although the auxiliary inverter acts as an active filter, the control algorithm of the inverter is easier than that of the active filters. In active filters, the reference current is calculated from the grid current using different methods [19-21], whereas this is more easily accomplished in the proposed system. In addition, the main purpose of utilizing the auxiliary inverter that is different from the active filter is an increased system efficiency compared to a single sixswitch three-phase inverter with an L filter.

The proposed system is modelled in MATLAB and analyzed in terms of the DC-link voltage, switching frequency, and filter inductance values for a $10-\mathrm{kW}$ output power. The characteristic curves of the system are given, and depending on these curves, the optimum system parameters are selected to provide a THD value of less than $5 \%$ of the grid current. The control of the system is quite simple because of the use of a basic L filter.

A prototype has been realized for a $10-\mathrm{kW}$ output power. The main inverter and auxiliary inverter are controlled via the dSPACE real-time controller and analogue controller, respectively.

\section{System description}

The proposed three-phase voltage-source grid-connected parallel inverter system is shown in Fig. 1. The system includes two voltage-source inverters. To obtain the required THD results, a single inverter should operate at relatively high switching frequencies, and in this case, the efficiency is lower owing to high switching losses. In the proposed system, the main inverter operates at a low switching frequency to obtain lower switching losses. Hence, the ripple in the main inverter current is large, and the THD value of the current is high.

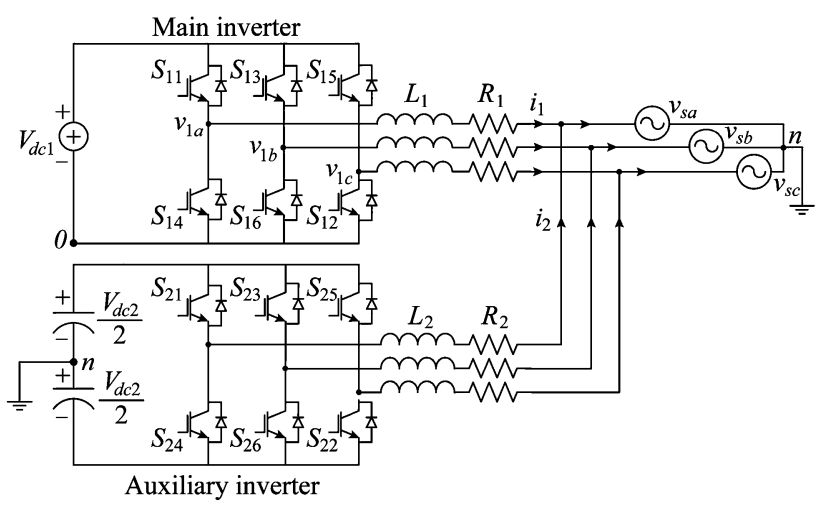

Fig. 1 Proposed grid-connected parallel inverter system 
The auxiliary inverter processes only reactive power to compensate the distortion in the main inverter current. The auxiliary inverter is controlled via the hysteresis current control (HCC). The operating frequency varies owing to $\mathrm{HCC}$, but it is always higher than that of the main inverter. The power processed by the auxiliary inverter is low. Hence, the losses on the auxiliary inverter are very low. The DC-link voltage of the auxiliary inverter is obtained from the grid via the current control.

The $\mathrm{L}$ filters are connected between the inverters and the grid. Although the L filter has less harmonic attenuation than the LC and LCL filters, it is preferred because of design and control simplicity.

\section{Modelling of proposed system}

The proposed system is modelled with the assumptions that the DC-link voltage is constant, the switching devices are ideal, and grid voltages are balanced.

In a three-phase symmetrical system without a neutral line,

$v_{s a}+v_{s b}+v_{s c}=0$

$i_{a}+i_{b}+i_{c}=0$

where $v_{s a}, v_{s b}, v_{s c}$ and $i_{a}, i_{b}, i_{c}$ define grid phase voltages and currents, respectively.

Applying the Kirchhoff's current law for each phase, three-phase circuit equations for each inverter are obtained as given in (3) and (4). The parameters $k, v_{1}, L_{1}, R_{1}$, and $i_{1}$ define the phase name $\{a, b, c\}$, phase voltage, inductance, inductor-equivalent series resistance, and phase current of the main inverter, respectively.

$v_{1 k}=L_{1} \frac{\mathrm{d} i_{1 k}}{\mathrm{~d} t}+R_{1} i_{1 k}+v_{s k}+v_{n 0}$

$v_{n 0}=\frac{1}{3}\left(v_{1 a}+v_{1 b}+v_{1 c}\right)$

Inverter phase voltages change with each leg-switching state. This can be defined as

$v_{1 k}=S_{1 k} V_{d c 1}= \begin{cases}V_{d c 1} & S_{1 k}=1 \\ 0 & S_{1 k}=0\end{cases}$

where $V_{d c 1}$ defines the DC-link voltage of the main inverter. The leg-switching state is defined by $S_{1}$. In the main inverter, if the upper switch is $\mathrm{ON}$, then $S_{1}=1$, and if the lower switch is $\mathrm{ON}$, then $S_{1}=0$.

By combining (3), (4), and (5), the mathematical model of the main inverter can be defined in a three-phase $(a b c)$ reference frame as:
$S_{1 k} V_{d c 1}=v_{s k}+R_{1} i_{1 k}+L_{1} \frac{\mathrm{d}}{\mathrm{d} t}\left(i_{1 k}\right)+\frac{S_{1 a}+S_{1 b}+S_{1 c}}{3} V_{d c 1}$

Because the middle point of the DC-link is connected to the grid neutral in the auxiliary inverter, it can be modelled as three single-phase grid-connected inverters, as shown in (7)-(9):

$v_{2 k}=L_{2} \frac{\mathrm{d} i_{2 k}}{\mathrm{~d} t}+R_{2} i_{2 k}+v_{s k}$

$v_{2 k}=S_{2 k} \frac{V_{d c 2}}{2}= \begin{cases}\frac{V_{d c 2}}{2} & S_{2 k}=1 \\ \frac{-V_{d c 2}}{2} & S_{2 k}=-1\end{cases}$

$S_{2 k} \frac{V_{d c 2}}{2}=v_{s k}+R_{2} i_{2 k}+L_{2} \frac{\mathrm{d}}{\mathrm{d} t}\left(i_{2 k}\right)$

The parameters $v_{2}, L_{2}, R_{2}$, and $i_{2}$ define the auxiliary inverter phase voltage, auxiliary inverter inductor, auxiliary inverter inductor-equivalent series resistance, and auxiliary inverter phase current, respectively. $S$ becomes 1 and -1 in the auxiliary inverter, unlike the main inverter.

The sum of the parallel inverter currents produces the grid current:

$i_{k}=i_{1 k}+i_{2 k}$

The state-space model of the grid-connected parallel inverters can be written using (6):

$\left\{\begin{array}{l}\frac{\mathrm{d} \boldsymbol{x}}{\mathrm{d} t}=\boldsymbol{A} \boldsymbol{x}+\boldsymbol{B u} \\ \boldsymbol{y}=\boldsymbol{C} \boldsymbol{x}\end{array}\right.$

where the state and input vectors are defined as:

$\boldsymbol{x}=\left[\begin{array}{llllll}i_{1 a} & i_{1 b} & i_{1 c} & i_{2 a} & i_{2 b} & i_{2 c}\end{array}\right]^{\mathrm{T}}$

$\boldsymbol{u}=\left[\begin{array}{c}S_{1 a} V_{d c 1}-v_{s a}-\left(\frac{S_{1 a}+S_{1 b}+S_{1 c}}{3}\right) V_{d c 1} \\ S_{1 b} V_{d c 1}-v_{s b}-\left(\frac{S_{1 a}+S_{1 b}+S_{1 c}}{3}\right) V_{d c 1} \\ S_{1 c} V_{d c 1}-v_{s c}-\left(\frac{S_{1 a}+S_{1 b}+S_{1 c}}{3}\right) V_{d c 1} \\ S_{2 a} \frac{V_{d c 2}}{2}-v_{s a} \\ S_{2 b} \frac{V_{d c 2}}{2}-v_{s b} \\ S_{2 c} \frac{V_{d c 2}}{2}-v_{s c}\end{array}\right]$

The state and input coefficient matrices are 


$$
\left\{\begin{aligned}
\boldsymbol{A} & =\left[\begin{array}{cc}
-\frac{R_{1}}{L_{1}} \boldsymbol{I}_{3 \times 3} & \mathbf{0}_{3 \times 3} \\
\mathbf{0}_{3 \times 3} & -\frac{R_{2}}{L_{2}} \boldsymbol{I}_{3 \times 3}
\end{array}\right] \\
\boldsymbol{B} & =\left[\begin{array}{cc}
\frac{1}{L_{1}} \boldsymbol{I}_{3 \times 3} & \mathbf{0}_{3 \times 3} \\
\mathbf{0}_{3 \times 3} & \frac{1}{L_{2}} \boldsymbol{I}_{3 \times 3}
\end{array}\right]
\end{aligned}\right.
$$

The output matrix $C$ is a unit matrix with a dimension of $6 \times 6$. The output variables are phase currents of parallel inverters, and the grid current defined in (10) can be calculated by adding the parallel inverter currents, as shown in Fig. 2.

\section{Control of proposed system}

The main function of the grid-connected inverter is to control the magnitude and phase angle of the grid current. The real power is controlled via the current magnitude, and active power is adjusted via the phase angle. In the proposed system, two parallel inverters are connected to the grid with an L filter, as shown in Fig. 3. Each inverter is controlled with a different control technique. In the main inverter, the output current is controlled using space-vector pulse-width modulation (SVPWM). This control technique is more appropriate for a three-wire three-phase inverter. The advantages of this technique are the constant switching frequency, low harmonic content, well-defined spectrum, optimum switching signals, and high DC-link voltage utilization. The optimum switching pattern provides a low switching number and low switching losses. The SVPWM technique is widely used in three-phase grid-connected inverters [22].

Because an auxiliary inverter eliminates the current ripple in the grid current, it requires a fast response. The HCC technique meets the requirements of the auxiliary inverter control. The nonlinear control technique, HCC, simultaneously realizes the current error compensation and PWM generation. It has an inherent peak-current protection, fast dynamic response, robustness against the parameter variation, and simplicity. Although the control algorithm is easy to implement, the sampling frequency should be high in the control system. Its performance depends on the hysteresis bandwidth, and the bandwidth affects the switching frequency [23, 24]. The control algorithm of the system is shown in Fig. 3.

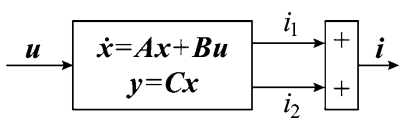

Fig. 2 Total current at the output of state-space equation
The main inverter reference current is the reference grid current. The grid current should be in phase with the grid voltage for the maximum active-power transfer. The threephase grid voltages are measured, and they are used to determine the grid angle $(\theta)$. Theta is determined via the SRF-PLL algorithm. The three-phase voltages are transformed to the $d q$ reference frame via the transformation matrix (16) in the phase detector. The $q$-component output of the grid voltage $\left(v_{q}\right)$ from the phase detector is used to detect grid angle. The error of $v_{q}$ is passed through the PI controller and added to the nominal frequency $\left(\omega_{n}\right)$ of the grid voltage. The reference value of $v_{q}^{*}$ is set to zero. The resultant signal is the grid frequency. The grid angle is determined by integrating the grid frequency, and is used to transform the three-phase voltage to the $d q$ reference frame at the beginning of the algorithm. The block diagram of the SRF-PLL algorithm is given in Fig. 4. Using $\theta$ and the reference power, the reference currents in the $d q$ coordinate system are calculated. The measured three-phase currents are transformed to the $d q$ coordinate system and compared with the measured $d q$ currents. By summing the output of the PI controllers $\left(K_{\mathrm{p}}=1.5, K_{\mathrm{I}}=0.001\right)$, the coupling components, and grid voltage, the inverter reference voltages in the $d q$ coordinate system are obtained, and these reference components are converted into $\alpha \beta$ components. The voltage-reference components in $\alpha \beta$ reference voltages are used in the SVPWM generation. Switching signals are generated using voltage references, the grid angle, and DClink voltage.

The main inverter current follows the reference grid current with an error owing to the high current ripple. This error causes a high THD value in the grid current. The auxiliary inverter is utilized to eliminate the current error and to decrease the THD value. To eliminate the current error, it is required to control the auxiliary inverter very rapidly. Therefore, the HCC technique is preferred to control the auxiliary inverter. The reference current of the auxiliary inverter is the main inverter current error.

$i_{2 j}^{*}=i_{1 j}^{*}-i_{1 j} \quad j=a, b, c$

$\boldsymbol{T}=\frac{2}{3}\left[\begin{array}{ccc}\cos (\omega t) & \cos \left(\omega t-\frac{2 \pi}{3}\right) & \cos \left(\omega t+\frac{2 \pi}{3}\right) \\ -\sin (\omega t) & -\sin \left(\omega t-\frac{2 \pi}{3}\right) & -\sin \left(\omega t+\frac{2 \pi}{3}\right)\end{array}\right]$

Because the DC-link consists of two capacitors connected in series, the voltages of capacitors should be regulated. The regulation is realized with a phase- $a$ current. In the positive cycle of the grid voltage, the upper capacitor voltage is regulated. The average voltage of the upper capacitor and the error between the reference and actual value is calculated at the beginning of the positive half- 

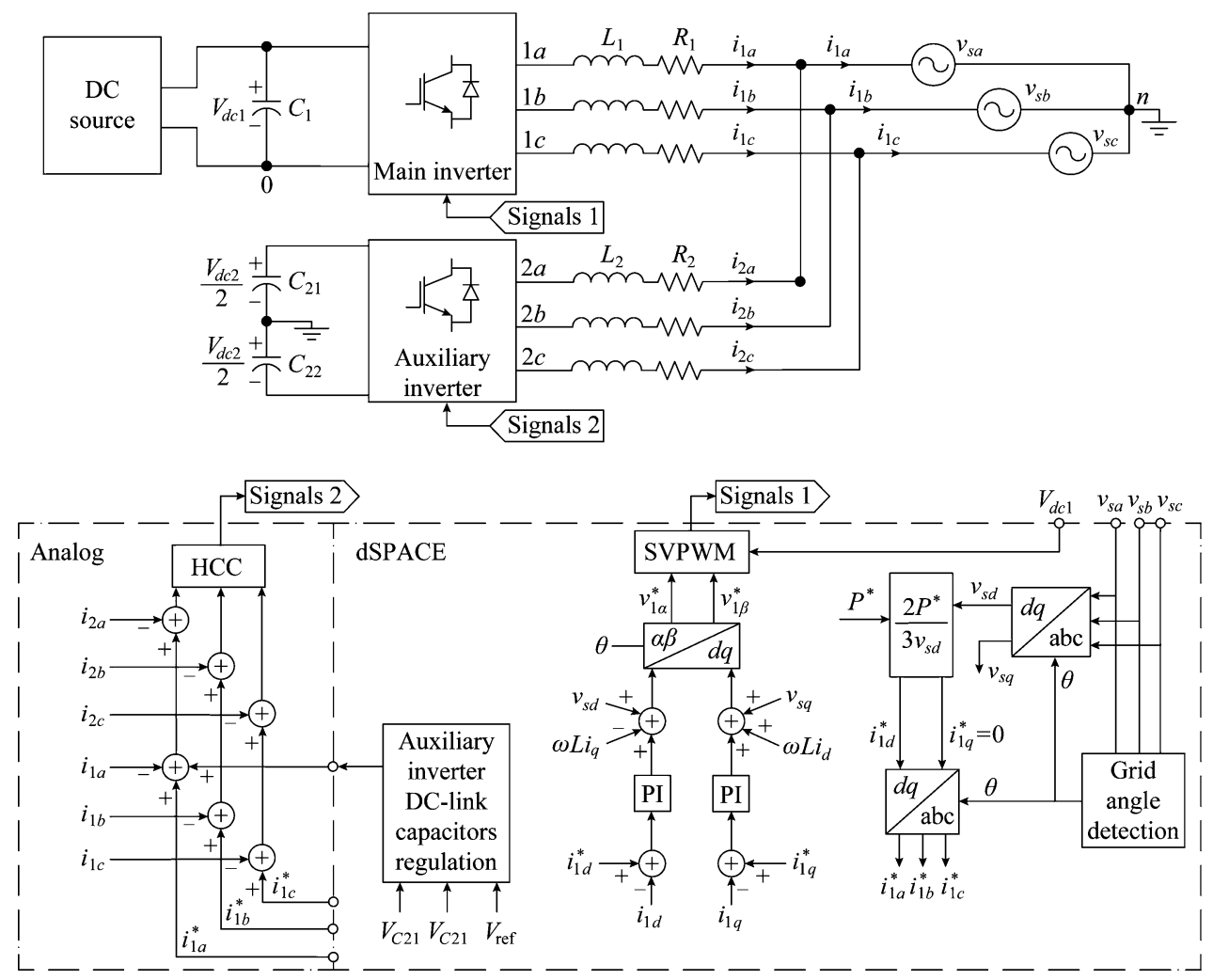

Fig. 3 Block diagram of three-phase grid-connected voltage-source parallel inverters and system control algorithm

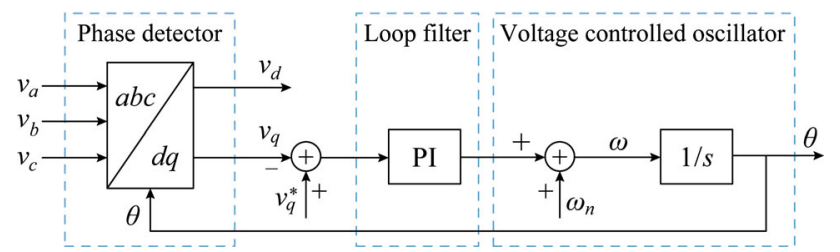

Fig. 4 SRF-PLL algorithm grid synchronization

cycle. The error is regulated with a PI controller $\left(K_{\mathrm{p}}=0.02, K_{\mathrm{I}}=5 \mathrm{e}^{-6}\right)$. The same algorithm is applied to the lower capacitor in the negative half-cycle of the grid voltage. The outputs of the PI controllers are added to the auxiliary inverter phase- $a$ current reference.

\section{Power loss calculation of inverters}

The energy loss of a semiconductor switch is the sum of the conduction losses $\left(E_{C O N D}\right)$ and switching losses $\left(E_{S W}\right)$.

$E_{T O T A L}=E_{C O N D}+E_{S W}$

The conduction losses of the insulated-gate bipolar transistor (IGBT) and diode are calculated from (18) and (19), as given in $[25,26]$.

$$
\begin{aligned}
& E_{I G B T, C O N D}=\int_{0}^{\pi} v_{C E s a t}(t) i_{C}(t) \mathrm{d} t \\
& E_{D I O D E, C O N D}=\int_{0}^{\pi} v_{f}(t) i_{f}(t) \mathrm{d} t
\end{aligned}
$$

where $v_{C E s a t}$ is the collector-emitter saturation voltage of IGBT, $i_{C}$ is the collector current of the IGBT, $v_{f}$ is the forward voltage drop of the diode, and $i_{f}$ is the diode forward current. $v_{C E s a t}$ is obtained from the $i_{C^{-}} v_{C E s a t}$ curve, and $v_{f}$ is obtained from the $i_{f}-v_{f}$ curve from the datasheet.

The switching-energy loss is the sum of turn-on $\left(E_{\text {on }}\right)$ and turn-off $\left(E_{o f f}\right)$ losses in the switching devices, as given by

$E_{S W}=E_{S W, o n}+E_{S W, o f f}$

The switching losses of the IGBT and diode are calculated depending on the voltage and current values from the $E_{\text {on }}$ and $E_{\text {off }}$ curves that are given in the datasheet. The current values are used in (18)-(20), and conduction energy losses are calculated. The power-loss calculation process is shown in Fig. 5. 


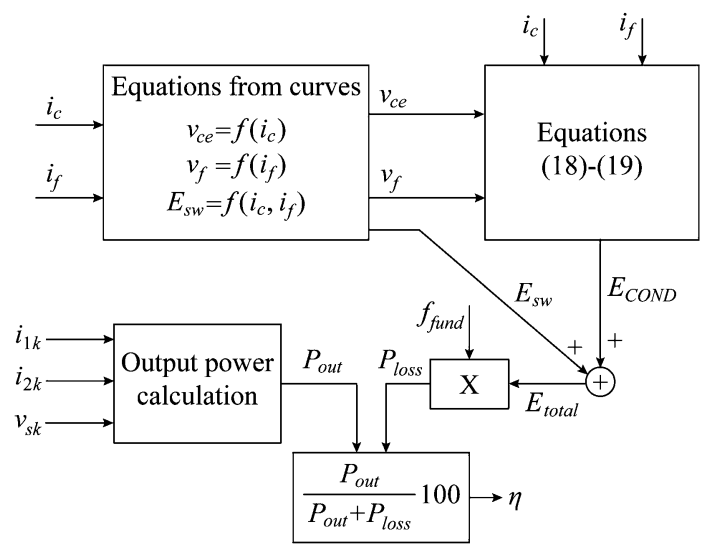

Fig. 5 Block diagram of power-loss calculation

\section{Design procedure}

The characteristic curves of the system are given in Figs. 6, 7, 8 and 9. These curves depend on various DClink voltages, filter inductances, hysteresis bandwidth values $(\Delta \mathrm{I})$, and switching frequencies $\left(f_{s w 1}\right)$, and are obtained using MATLAB for a $220 \mathrm{~V}$ grid voltage, $50-\mathrm{Hz}$ grid frequency, and $10 \mathrm{~kW}$ output power. The parameters are determined to obtain low THD and low switching frequency in the auxiliary inverter. The characteristic curves of the main inverter and 5\% THD limiting surface are shown in Figs. 6 and 7. From Fig. 6, it is seen that the $\mathrm{THD}_{1}$ decreases when $f_{s w 1}$ increases. The operation below the THD limiting surface can be ensured using different inductance and frequency values. For $f_{s w 1}=9 \mathrm{kHz}$, the THD variation is shown according to the DC-link voltage $V_{d c 1}$ and filter inductance $L_{1}$ in Fig. 7. It is seen that the THD increases with increased DC-link voltage. In contrast, the increase of the $L_{1}$ filter inductor results in a decrease in the THD value.
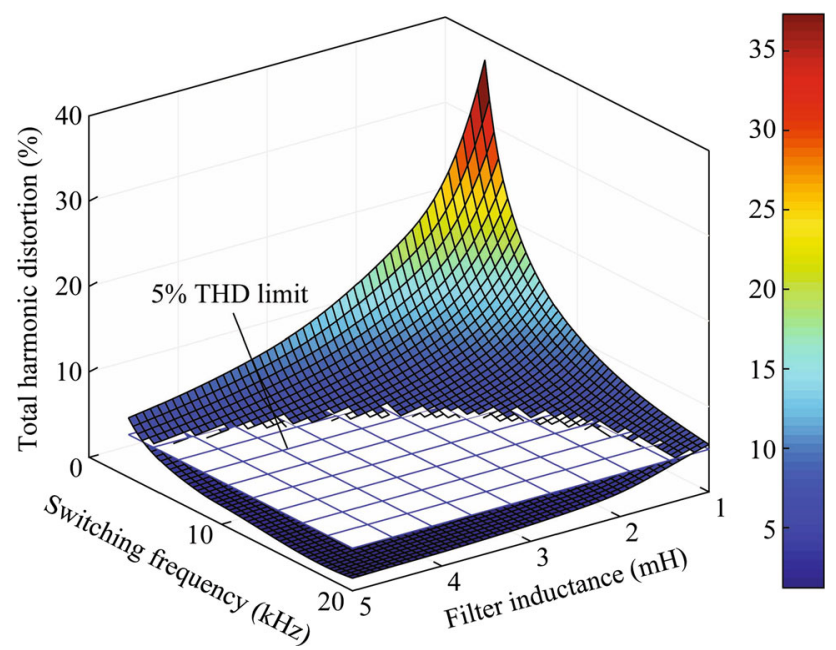

Fig. 6 Main inverter current THD for different values of $L_{1}$ and $f_{s w 1}$
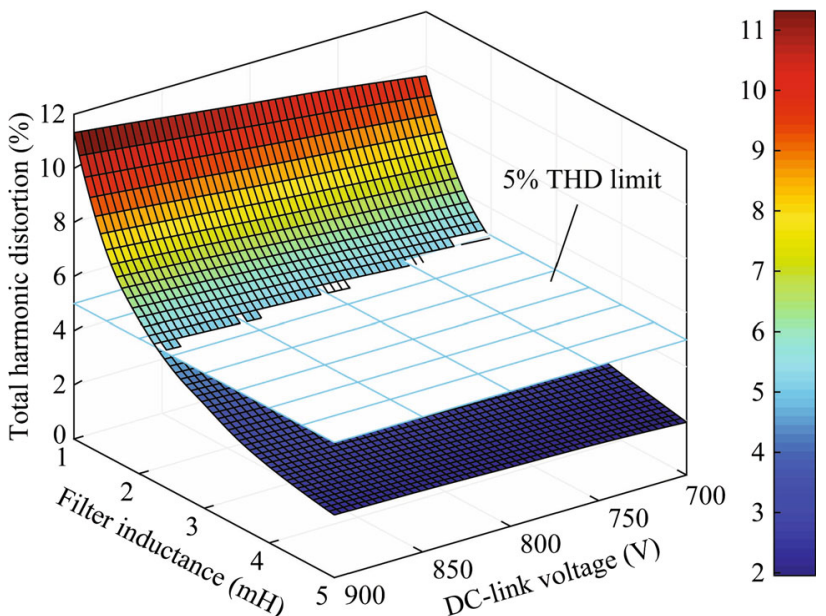

Fig. 7 Main inverter current THD for different values of $V_{d c}$ and $L_{1}$ for $f_{s w 1}=9 \mathrm{kHz}$
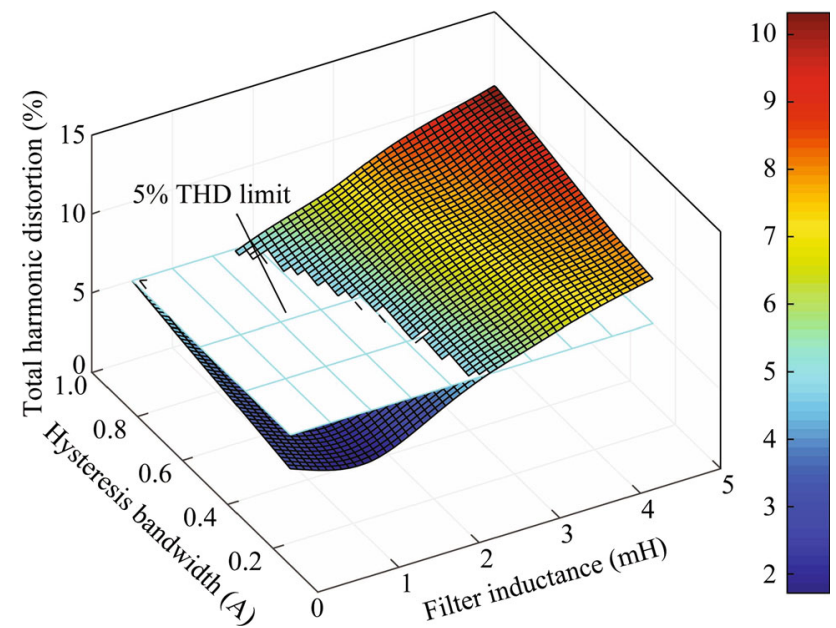

Fig. 8 Grid-current THD for different values of $\Delta I$ and $L_{2}$

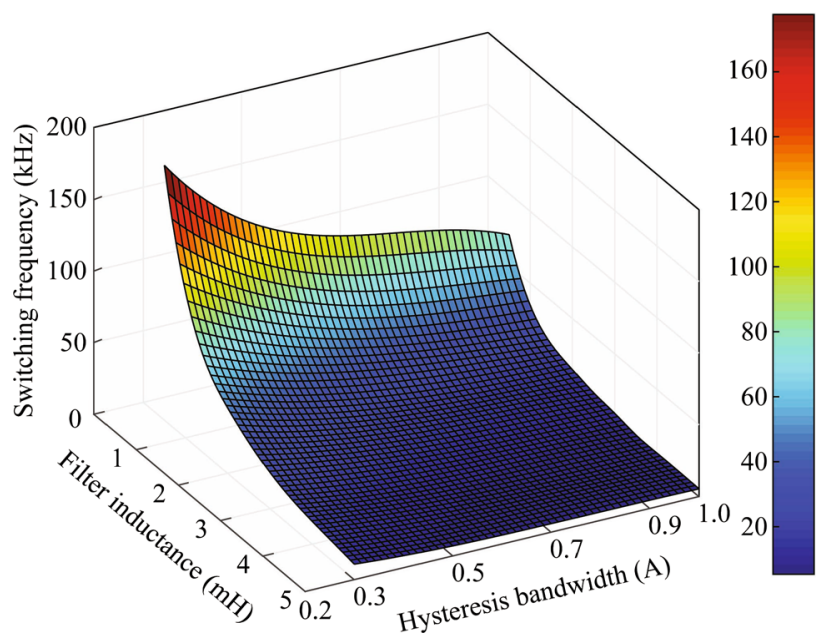

Fig. 9 Auxiliary inverter average switching frequency for different values of $\Delta I$ and $L_{2}$ 
If the energy is transferred to the grid using only the main inverter, $L_{1}$ and/or $f_{s w 1}$ must be high enough to provide the required THD value. The proper parameters for this case can be selected from the curves. In the proposed parallel-inverter system, the goal is to decrease the switching losses of the main inverter regardless of the gridcurrent THD value. The auxiliary inverter is utilized to compensate the grid current harmonics in order to meet harmonic standards. The main inverter-current error becomes the auxiliary inverter reference current. Therefore, the selection of $L_{1}$ and $f_{s w 1}$ is important to determine the performance of the auxiliary inverter because it determines the current of the auxiliary inverter.

To compensate for the dead-time, inductor, and switch conduction voltage drops, and to control stability, a $700 \mathrm{~V}$ DC voltage was selected. The main inverter filter inductor was selected as $L_{1}=3 \mathrm{mH}$. If the main inverter is operated as a standalone, the switching frequency should be selected to be approximately $9 \mathrm{kHz}$ to meet the 5\% THD limit. In the proposed method, the switching frequency of the main inverter is selected as $f_{s w 1}=3 \mathrm{kHz}$ in order to decrease switching losses, and the ripple of the grid current is eliminated via an auxiliary inverter.

In the auxiliary inverter, the IGBTs are switched at high voltage. Thus, the switching frequency is an important limitation. The auxiliary inverter currents are low, but the current rise rate is high. Therefore, the selection of the auxiliary inverter inductance $L_{2}$ and HCC bandwidth $\Delta I$ is important. $L_{2}$ and $\Delta I$ values that provide a $5 \%$ THD limit and achievable $f_{s w 2}$ are selected from the characteristic curves as $L_{2}=2 \mathrm{mH}$, and $\Delta I=0.7 \mathrm{~A}$. $f_{s w 2}$ is not constant, and varies during the grid period. The average value of $f_{s w 2}$ is approximately $20 \mathrm{kHz}$.

The control performance depends on the bandwidth value of HCC. The increase in the bandwidth value degrades the control performance, and the THD value of the grid current increases, as shown in Fig. 8. A narrowing of the hysteresis bandwidth decreases the THD, but increases the switching frequency $f_{s w 2}$, as shown in Figs. 8 and 9.

\section{Simulation results}

The proposed system was simulated in MATLAB/ Simulink. The simulation parameters were determined from characteristic curves in Figs. 6, 7, 8 and 9. The threephase current waveforms of the main inverter operating standalone at $f_{s w 1}=3 \mathrm{kHz}$ are shown in Fig. 10. In this case, THD is $14 \%$ and does not meet the standards. The auxiliary inverter current that compensates the main inverter current is shown in Fig. 11.

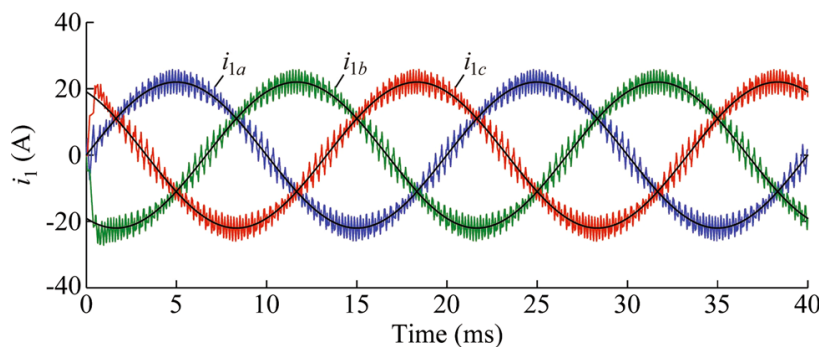

Fig. 10 Three-phase currents of the main inverter

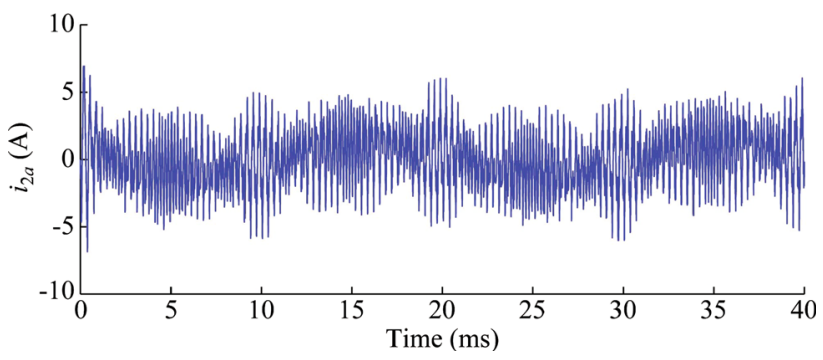

Fig. 11 Phase- $a$ current of the auxiliary inverter

Three-phase grid currents produced by two parallel inverters are given in Fig. 12. The total grid current has a 4.33\% THD that meets the standards. The auxiliary inverter average switching frequency is approximately 20 $\mathrm{kHz}$. Even though the average switching frequency appears to be high, the switching losses are negligible owing to the low level of the auxiliary inverter current.

Figure 13 shows simulation results of grid synchronization for three fundamental periods. Three-phase grid voltages and the grid angle, which is determined through PLL, are given in Fig. 13a and b, respectively. As seen in Fig. 13b, the grid angle changes over $0-2 \pi(\mathrm{rad})$. The angle is $4 \pi / 3$ (rad) when the phase- $a$ voltage is zero, phase$b$ voltage is negative, and phase- $c$ voltage is positive. The angle reaches $2 \pi$ rad when the phase- $a$ voltage becomes a maximum and other phase voltages are equal. The angle varies in $2 \pi(\mathrm{rad})$ for $20 \mathrm{~ms}$, which is the fundamental period of the grid voltage.

Figure 14 shows the DC-link capacitor voltages of the auxiliary inverter. The DC-link consists of two seriesconnected capacitors, and the middle point is connected to the grid neutral. Therefore, the voltages of the capacitors

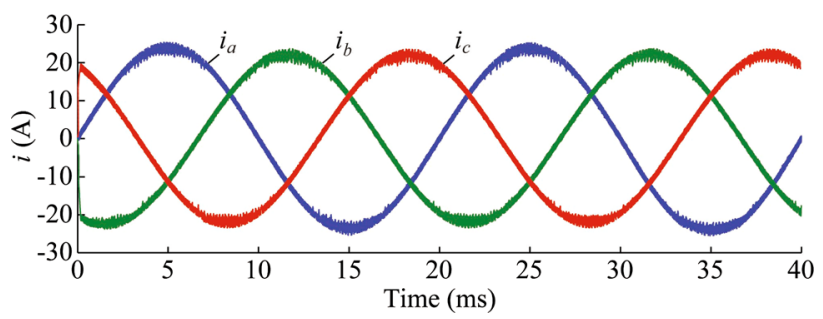

Fig. 12 Three-phase grid currents of parallel inverter 


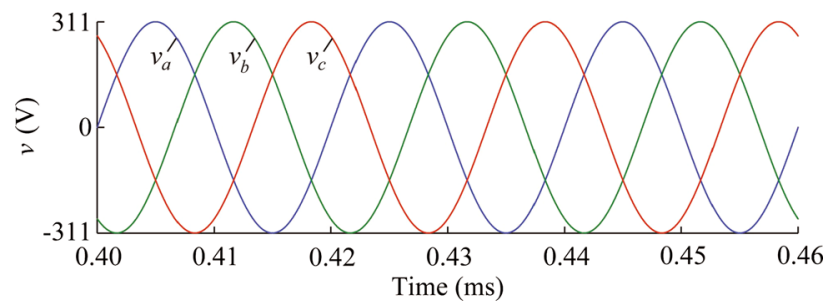

(a) Three-phase voltages

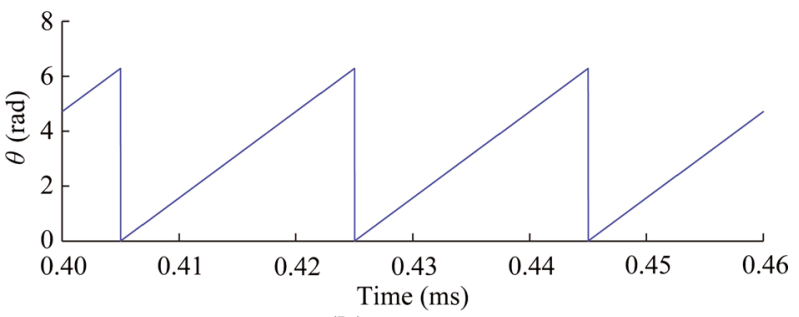

(b) Grid angle

Fig. 13 Grid synchronization

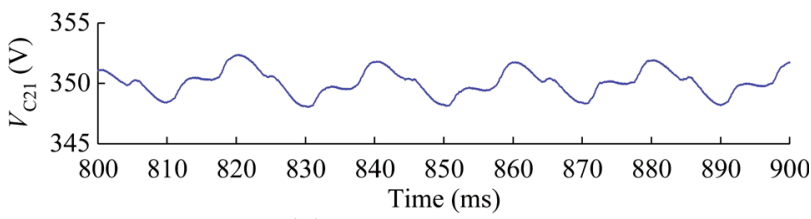

(a) Upper capacitor voltage

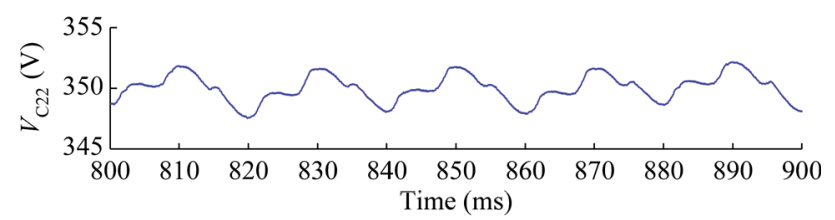

(b) Lower capacitor voltage

Fig. 14 Auxiliary inverter DC-link voltage

should be regulated. The regulation can be seen in Fig. 14 . Each capacitor voltage varies between $348 \mathrm{~V}$ and $352 \mathrm{~V}$. The total voltage ripple of $4 \mathrm{~V}$ is observed in each capacitor voltage. The upper and lower capacitor voltages move in opposite directions. The upper capacitor voltage rises, while the lower capacitor voltage decreases for 10 ms.

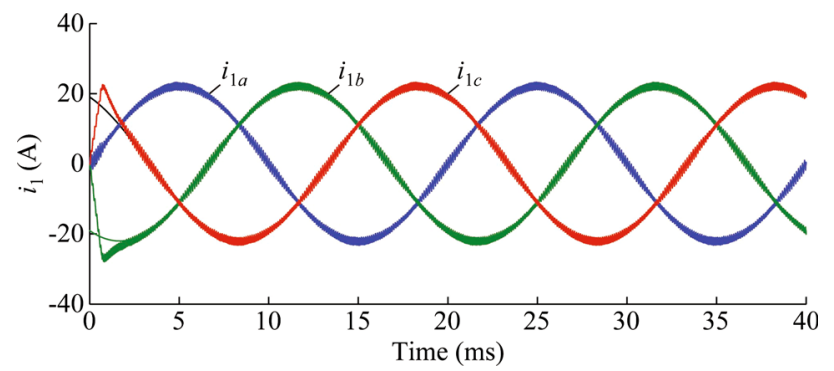

Fig. 15 Three-phase grid currents of the main inverter at $f_{s w}=9 \mathrm{kHz}$
Figure 15 shows the three-phase grid currents for the standalone operation of the main inverter at $f_{s w}=9 \mathrm{kHz}$. A similar THD value is obtained using the proposed method, as shown in Fig. 13. In this case, the main inverter operates at a $3 \mathrm{kHz}$ switching frequency, and switching losses are thus decreased by a factor of three times.

To evaluate the efficiency improvement of the proposed parallel inverter system, the efficiency of parallel inverters is calculated with $V_{d c}=700 \mathrm{~V}, L_{1}=3 \mathrm{mH}, L_{2}=2 \mathrm{mH}$, $f_{s w 1}=3 \mathrm{kHz}$, and $\Delta I=0.7 \mathrm{~A}$, and the efficiency of the standalone inverter is calculated with $V_{d c}=700 \mathrm{~V}$, $L_{1}=3 \mathrm{mH}$, and $f_{s w 1}=9 \mathrm{kHz}$. Figure 16 illustrates the efficiency curves of the proposed system and the standalone operation of the main inverter for different output power levels. The filter inductor losses are not taken into consideration. The standalone inverter efficiency is $97.6 \%$, and the parallel-inverter system efficiency is $98.6 \%$ for the rated power. The efficiency is increased by $1 \%$ with the proposed control of the parallel inverters.

\section{Experimental study}

A laboratory prototype of the proposed system is realized for a $10 \mathrm{~kW}$ output power. The control algorithm of the main inverter was developed in MATLAB/Simulink and implemented using dSPACE. The efficiency and THD measurements were acquired using a HIOKI 3390 energy analyzer.

The main inverter is supplied using a $700 \mathrm{~V}$ DC source, and the auxiliary inverter regulates its DC voltage through the grid with an active rectifier operation. The hysteresis control of the auxiliary inverter is implemented using analogue circuitry.

The system parameters and components used in the prototype are given in Table 1. The three-phase current waveforms of the main inverter operating standalone at $f_{s w 1}=9 \mathrm{kHz}$ are shown in Fig. 17. The measured THD and efficiency values for this operation are $4.46 \%$ and $97.45 \%$, respectively.

To decrease the switching losses, the main inverter switching frequency is decreased to $3 \mathrm{kHz}$. The three-phase

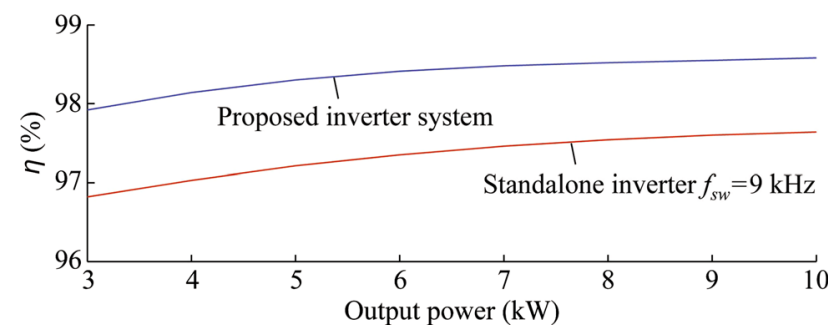

Fig. 16 Efficiency curves for the standalone inverter $f_{s w}=9 \mathrm{kHz}$ and proposed inverter system 
Table 1 Summary of the proposed system

\begin{tabular}{lll}
\hline Component & Main inverter & Auxiliary inverter \\
\hline Switch & PM50CL1A120 IPM & FGL40N120AND IGBT \\
$f_{s w}$ & $3 \mathrm{kHz}$ & $20 \mathrm{kHz}$ (average) \\
$V_{d c}$ & $700 \mathrm{~V}$ & $700 \mathrm{~V}$ \\
$L_{f i t}$ & $3 \mathrm{mH}$ & $2 \mathrm{mH}$ \\
$P_{i n v}$ & $10 \mathrm{~kW}$ & - \\
\hline
\end{tabular}

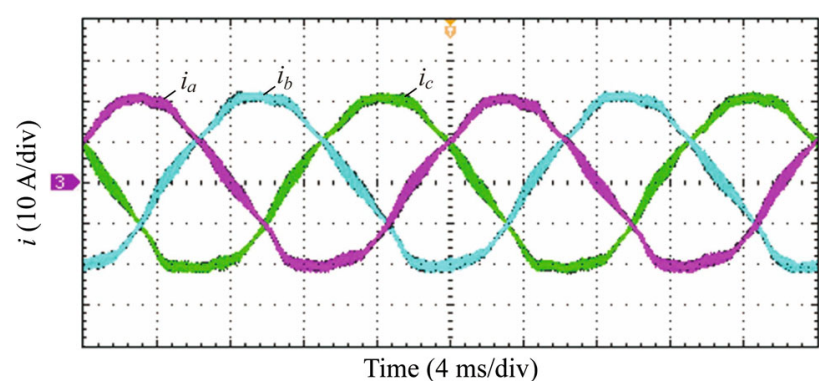

Fig. 17 Grid currents of the standalone inverter at $f_{s w}=9 \mathrm{kHz}$

currents of this operation are shown in Fig. 18. As can be clearly seen from the figure, the low switching frequency causes a high current ripple. The measured THD and efficiency of this operation are $14.7 \%$ and $98.36 \%$, respectively.

To lower the THD of the grid current, an auxiliary inverter is operated. In Fig. 19, the main inverter current (Ch4), auxiliary inverter current (Ch3), and grid current (Ch2) are shown with respect to the related phase voltage (Ch1). Although there is a high current ripple in the main inverter current, this ripple is eliminated in the grid current by the auxiliary inverter. Three-phase grid currents are shown in Fig. 20.

Voltage waveforms of the DC-link capacitors in the auxiliary inverter are shown in Fig. 21. The voltages are measured from the output of the voltage sensors. In the experimental setup, two LEM LV25-P voltage sensors are used to measure each capacitor voltage. It has a 2500:1000 conversion ratio. The resistors used in the measurement

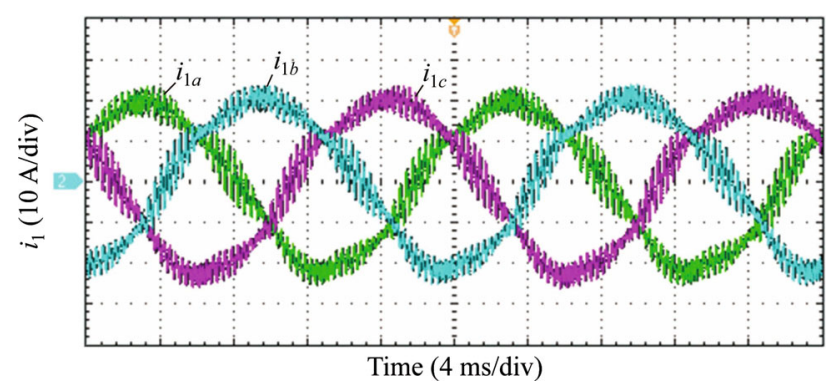

Fig. 18 Three-phase currents of the main inverter for $f_{s w}=3 \mathrm{kHz}$

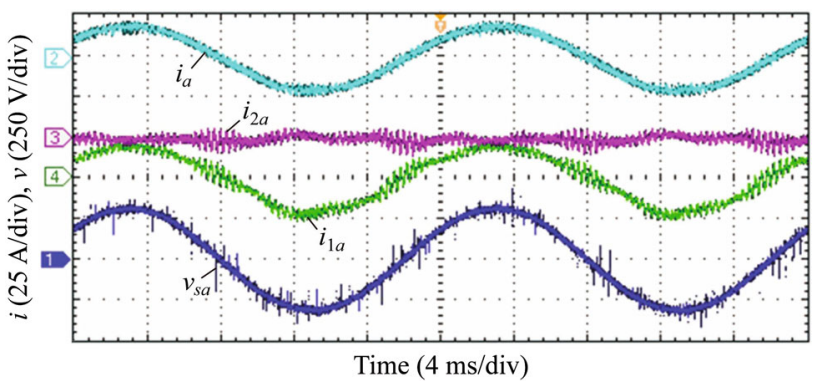

Fig. 19 Proposed system operation with respect to phase voltage

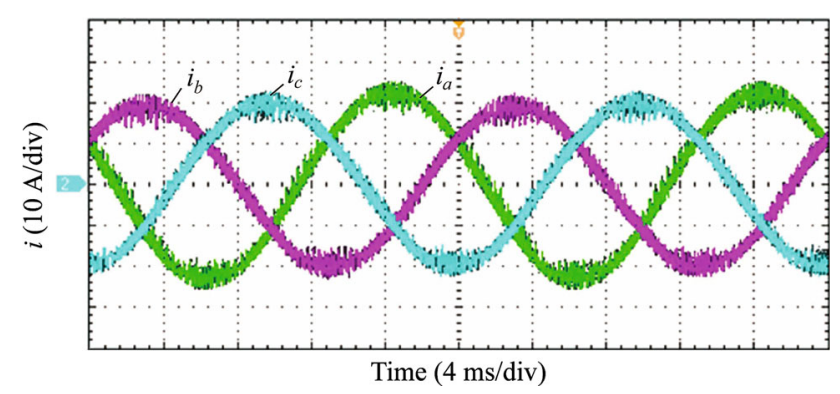

Fig. 20 Three-phase grid currents of the proposed system

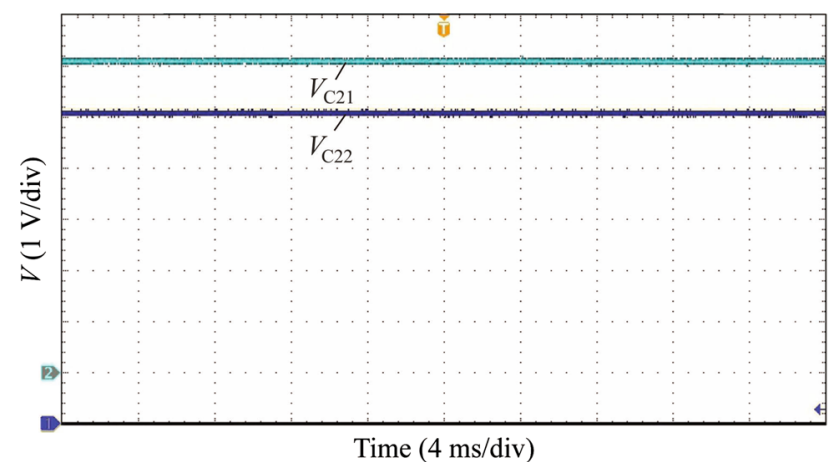

Fig. 21 DC-link capacitor voltages of the auxiliary inverter

board are $47 \mathrm{k} \Omega$ and $330 \Omega$. Thus, the ratio of the actual and measured voltage is 57.14. The actual capacitor voltage of $350 \mathrm{~V}$ is measured at approximately $6.1 \mathrm{~V}$, as seen in Fig. 21.

The measured THD and efficiency values are $4.33 \%$ and $97.86 \%$ in the proposed system, respectively. Experimental

Table 2 Experimental results of the proposed system

\begin{tabular}{llllll}
\hline System & $\begin{array}{l}\text { Efficiency } \\
(\%)\end{array}$ & $\begin{array}{l}\text { THD } \\
(\%)\end{array}$ & $\begin{array}{l}P_{\text {in }} \\
(\mathrm{kW})\end{array}$ & $\begin{array}{l}P_{\text {out }} \\
(\mathrm{kW})\end{array}$ & $\begin{array}{l}P_{\text {loss }} \\
(\mathrm{W})\end{array}$ \\
\hline $\begin{array}{l}\text { Main inverter } \\
(3 \mathrm{kHz})\end{array}$ & 98.36 & 14.70 & 10.110 & 9.945 & 165 \\
$\begin{array}{c}\text { Main inverter } \\
(9 \mathrm{kHz})\end{array}$ & 97.45 & 4.46 & 10.340 & 10.076 & 264 \\
$\begin{array}{l}\text { Proposed system } \\
\text { Propos }\end{array}$ & 97.86 & 4.33 & 10.170 & 9.953 & 217 \\
\hline
\end{tabular}


Table 3 Losses of the proposed system

\begin{tabular}{lllll}
\hline System & $\begin{array}{l}\text { Total } \\
\text { losses } \\
(\mathrm{W})\end{array}$ & $\begin{array}{l}\text { IGBT } \\
\text { losses } \\
(\mathrm{W})\end{array}$ & $\begin{array}{l}\text { Aux. } \\
\text { Inv. + filter } \\
\text { losses (W) }\end{array}$ & $\begin{array}{l}\text { Main Inv. } \\
\text { filter losses } \\
(\mathrm{W})\end{array}$ \\
\hline $\begin{array}{c}\text { Main } \\
\text { inverter } \\
(3 \mathrm{kHz})\end{array}$ & 165 & 126 & - & 39 \\
$\begin{array}{c}\text { Main } \\
\text { inverter } \\
(9 \mathrm{kHz})\end{array}$ & 264 & 240 & - & 24 \\
$\begin{array}{c}\text { Proposed } \\
\text { system }\end{array}$ & 217 & 126 & 52 & 39 \\
\hline
\end{tabular}

results taken from the proposed system are given in Table 2.

The measured efficiencies given in Table 2 are slightly different from the simulation study results shown in Fig. 15. This difference is caused by the filter inductor losses. The inductors are modelled as ideal elements in the simulation. However, in the experimental study, it is seen that inductor losses affect the overall system efficiency.

The software Melcosim was used to estimate intelligent power module (IPM) losses of the main inverter. For a 9 $\mathrm{kHz}$ operating frequency, the IPM losses of the main inverter are calculated as $240 \mathrm{~W}$, and for a $3 \mathrm{kHz}$ operation, the IPM losses are calculated as $126 \mathrm{~W}$. According to the Melcosim software results, the losses of the proposed system are as given in Table 3.

It can be seen that filter inductor losses are an important factor that determines the efficiency of grid-connected inverter systems. The losses due to the filter inductor depends on many factors. From the experimental results, it is observed that the main filter inductor losses are increased when the main inverter is operated at lower frequency.

\section{Conclusion}

In this paper, a new three-phase grid-connected converter system was proposed. The proposed system includes two inverters. The main inverter operates at a low switching frequency and transfers all of the active energy from a DC source to the grid. The low-power auxiliary inverter operates at a high frequency to compensate for the grid-current ripple. The goal is to produce a grid current with a low THD value and to obtain a higher efficiency.

The proposed system was modelled in MATLAB and analyzed in terms of the DC-link voltage, switching frequency, and filter-inductance values for a $10-\mathrm{kW}$ output power. The characteristic curves of the system are given, and depending on these curves, the optimum system parameters are selected to provide a THD value of less than $5 \%$ of the grid current. Owing to the operation at low switching frequencies, the main inverter switching losses decrease compared with a single inverter for the same THD value that is obtained from parallel inverters. According to the experimental results, the proposed system efficiency and grid current THD value are measured as $97.86 \%$ and $4.33 \%$, respectively, whereas for a single two-level inverter, the values are $97.46 \%$ and $4.46 \%$, respectively. The proposed system provides a $0.4 \%$ efficiency improvement for a $10-\mathrm{kW}$ grid-connected system. A higher efficiency value can be obtained using a more efficient filter inductor design and using different solid-state switching devices.

Acknowledgements This work was supported by The Scientific and Technological Research Council of Turkey (TUBITAK) (No. 110E212).

Open Access This article is distributed under the terms of the Creative Commons Attribution 4.0 International License (http:// creativecommons.org/licenses/by/4.0/), which permits unrestricted use, distribution, and reproduction in any medium, provided you give appropriate credit to the original author(s) and the source, provide a link to the Creative Commons license, and indicate if changes were made.

\section{References}

[1] Blaabjerg F, Chen Z, Kjaer SB (2004) Power electronics as efficient interface in dispersed power generation systems. IEEE Trans Power Electron 19(5):1184-1194

[2] Blaabjerg F, Teodorescu R, Chen Z et al (2004) Power converters and control of renewable energy systems. In: Proceedings of international conference power electronics (ICPE'04), Pusan, Korea, 18-22 October 2004, pp 1-20

[3] Guo X, He R, Jian J et al (2016) Leakage current elimination of four-leg inverter for transformerless three-phase PV systems. IEEE Trans Power Electron 31(3):1841-1846

[4] Hintz A, Prasanna UR, Rajashekara K (2016) Comparative study of the three-phase grid-connected inverter sharing unbalanced three-phase and/or single-phase systems. IEEE Trans Ind Appl 52(6):5156-5164

[5] Vechiu I, Camblong H, Tapia G et al (2007) Control of four leg inverter for hybrid power system applications with unbalanced load. Energy Convers Manag 48(7):2119-2128

[6] Isen E, Bakan AF (2011) Comparison of hysteresis controlled three-wire and split-link four-wire grid connected inverters In: Proceedings of electrical engineering/electronics, computer, telecommunications and information technology conference (ECTI-CON'11), Khon Kaen, Thailand, 17-19 May 2011, pp 727-730

[7] Boue ABR, Valverde RG, Vila FAR et al (2012) An integrative approach to the design methodology for 3-phase power conditioners in photovoltaic grid-connected systems. Energy Convers Manag 56:80-95

[8] Jayalath S, Hanif M (2017) Generalized LCL-filter design algorithm for grid-connected voltage-source inverter. IEEE Trans Ind Electron 64(3):1905-1915 
[9] Yang S, Lei Q, Peng FZ (2011) A robust control for grid-connected voltage-source inverters. IEEE Trans Ind Electron 58(1):202-212

[10] Beres R, Wang X, Blaabjerg F et al (2014) Comparative evaluation of passive damping topologies for parallel grid-connected converters with LCL filters. In: Proceedings of the 2014 international power electronics conference (IPEC'14), Hiroshima, Japan, 18-21 May 2014, pp 3320-3327

[11] Pena-Alzola R, Liserre M, Blaabjerg F et al (2013) Analysis of the passive damping losses in LCL-filter-based grid converters. IEEE Trans Power Electron 28(6):2642-2646

[12] Said-Romdhane MB, Naouar MW, Slama-Belkhodja I et al (2016) Robust active damping methods for LCL filter-based grid-connected converters. IEEE Trans Power Electron 32(9):6739-6750

[13] Sebaaly F, Vahedi H (2016) Sliding mode fixed frequency current controller design for grid-connected NPC inverter. IEEE J Emerg Sel Top Power Electron 4(4):1397-1405

[14] Pouresmaeil E, Miracle DM, Bellmunt OG (2012) Control scheme of three-level NPC inverter for integration of renewable energy resources into AC grid. IEEE Syst J 6(2):242-253

[15] Yazdani D, Pahlevaninezhad M, Bakhshai A (2009) Threephase grid synchronization techniques for grid connected converters in distributed generation systems. In: Proceedings of IEEE international symposium on industrial electronics, (ISIE), Seoul, Korea, 5-8 July 2009, pp 1105-1110

[16] Wang YF, Li YW (2011) Grid Synchronization PLL based on cascaded delayed signal cancellation. IEEE Trans Power Electron 26(7): 1987-1997

[17] Golestan S, Guerrero JM, Vasquez JC (2017) Three-phase PLLs: a review of recent advances. IEEE Trans Power Electron 32(3):1894-1907

[18] Golestan S, Guerrero JM, Vasquez JC (2017) A robust and fast synchronization technique for adverse grid conditions. IEEE Trans Ind Electron 64(4):3188-3194

[19] Mannen T, Fujita H (2016) A DC capacitor voltage control method for active power filters using modified reference including the theoretically derived voltage ripple. IEEE Trans Ind Appl 52(5):4179-4187

[20] Martinek R, Vanus J, Bilik P et al (2016) An efficient control method of shunt active power filter using adaline. In: Proceedings of the 14th IFAC conference on programmable devices and embedded systems (PDES'16), Brno, Czech Republic, 5-7 October 2016, pp 352-357

[21] Mahanty R (2014) Indirect current controlled shunt active power filter for power quality improvement. Electr Power Energy Syst 62:441-449
[22] Zeng Q, Chang L (2008) Development of an SVPWM-based predictive current controller for three-phase grid-connected VSI. In: Proceedings of industry applications conference, Hong Kong, China, 2-6 October 2005, pp 2395-2400

[23] Ghani P, Chiane AA, Kojabadi HM (2010) An adaptive hysteresis band current controller for inverter base DG with reactive power compensation. In: Proceedings of power electronic \& drive systems \& technologies conference (PEDSTC'10), 17-18 Feb 2010, Tehran, Iran, pp 429-434

[24] Sonawane A, Gawande SP, Kadwane SG et al (2016) Nearly constant switching frequency hysteresis-based predictive control for distributed static compensator applications. IET Power Electron 9(11):2174-2185

[25] Zhou Z, Khanniche MS, Igic S (2005) A fast power loss calculation method for long real time thermal simulation of IGBT modules for a three-phase inverter system. In: Proceedings of power electronics and applications (EPE'05), Dresden, Germany, 11-14 September 2005, pp 1-10

[26] Graovac D, Pürschel M (2009) IGBT power losses calculation using the data-sheet parameters. Infineon Application Note v1.1

Evren ISEN received B.S. degree in electrical engineering, M.S. degree in electrical engineering, and Ph.D. degree in electrical engineering from Yildiz Technical University, Yildiz, Turkey, in 2003, 2005, and 2012, respectively. Since 2012, he has been working as an Assistant Professor in the Department of Electrical and Electronics Engineering, Kirklareli University. His research interests include grid-connected inverters and photovoltaic energy conversion systems in power electronics.

Ahmet Faruk BAKAN received B.S. degree in electronics and communication engineering, M.S. degree in electrical engineering, and Ph.D. degree in electrical engineering from Yildiz Technical University, Yildiz, Turkey, in 1994, 1997, and 2002, respectively. Since 2012, he has been working as an Associate Professor in the Department of Electrical Engineering, Yildiz Technical University. He has published more than 20 journal and conference papers in the area of power electronics. He was also employed in several research projects concerning power electronics. His research interests include direct torque control, photovoltaic inverters, welding machines, and soft-switching techniques in power electronics. 